\title{
Studies on Melanin
}

\section{Malignant Melanoma in Japan}

By

\author{
Yoshio Yoshida \\ (吉田良夫)
}

(From the Department of Dermatology, Faculty of Medicine, Tohoku University, Sendai; Director: Prof. M. I tô)

(Received for publication, August 29, 1952)

In a previous report, several cases of malignant melanoma recently experienced in the author's Clinic were reported and studied chiefly from the histological and histochemical points of view (Itô and Yoshida ${ }^{1}$ ). In this paper, a statistical study of 206 cases of malignant melanoma collected from Japanese literature, especially of 78 cases originated in the skin was made as compared with that in the white or black races. As the statistical studies of malignant melanoma in Europe we have the treatises by Dieterich ${ }^{2)}$ (1887) and Luther (1900). Seuqeira and Vint ${ }^{3)}$ (1934) observed the malignant melanomas in the natives of East and Ventral Africa. In U.S.A. Pack et al.4 (1947) and Macdonald ${ }^{5)}$ (1948) published. statistical data of malignant melanomas from their own points of view. In Japan, there are similar studies by Kawanishi ${ }^{6}$ (1928), Miyata $^{7 \prime}$ (1935), Amano ${ }^{81}$ (1941) and Fujita') (1948). But no treatise can be found in which the investigation of the differences between the white, yellow and black races was made.

The author collected 206 cases of malignant melanoma from Japanese literature from 1890 through 1949. These cases are mostly Japanese with a few exceptional cases of other yellow races, Chinese and Korean. On the other hand, there were reported 349 cases of malignant melanoma in Connecticut, U.S.A., from 1935 through 1946 (Macdonald), 145 cases in German literature from 1860 to 1882 (Dieterich) and 951 cases at the Memorial Hospital in New York from 1917 to 1946 (Pack et al.). From these facts, it cannot be denied that malignant melanomas are more rarely found in the Japanese than in the white races.

Malignant melanoma has accounted for .93 per cent of the total cancer cases in Connecticut for the past twelve years (Macdonald). Though no similar statistic datum can be found in Japan, Nagayo ${ }^{\mathbf{1 0}}$ collected 30,782 cases of total cancer by inquiring of chief hospitals in Japan (1933). Therefore it is presumed that the ratio of malignant 
melanoma to total cancer in Japan is lower than that in Connecticut.

TABLE I

Incidence of Malignant Melnoma by Site, Sex and Age

(Collected from Japanese literature)

\begin{tabular}{|c|c|c|c|c|c|c|c|c|c|c|c|c|c|c|c|c|c|c|c|c|c|}
\hline \multirow{2}{*}{ Site } & \multirow{2}{*}{ 触 } & \multirow{2}{*}{$\stackrel{0}{\frac{\pi}{\pi}}$} & \multirow{2}{*}{ 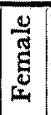 } & \multicolumn{2}{|c|}{$\begin{array}{c}\text { Under } \\
9\end{array}$} & \multicolumn{2}{|c|}{$10-19$} & \multicolumn{2}{|c|}{$20-29$} & \multicolumn{2}{|c|}{$30-39$} & \multicolumn{2}{|c|}{$40-49$} & \multicolumn{3}{|c|}{$50-59$} & \multicolumn{2}{|c|}{$60-69$} & \multicolumn{2}{|c|}{$70+$} & \multirow{2}{*}{ N.S. } \\
\hline & & & & $\mathbf{M}$ & $F$ & $\mathbf{M}$ & $\mathrm{F}$ & $\mathbf{M}$ & $F$ & $\mathbf{M}$ & F. & $\mathbf{M}$ & $\mathbf{F}$ & $\mathbf{M}$ & $?$ & $\mathbf{F}$ & $\mathbf{M}$ & $\mathbf{F}$ & $\mathbf{M}$ & $F$ & \\
\hline \multicolumn{22}{|l|}{ Skin } \\
\hline Head and neck & 21 & 12 & 9 & & & 1 & 2 & 1 & & 1 & 1 & 1 & & 4 & & 1 & 4 & 4 & & 1 & \\
\hline Upper ext. & 11 & 5 & 6 & & & & & 1 & & & & 1 & 2 & 1 & & 3 & 2 & 1 & & & \\
\hline Trunk & 13 & 11 & 2 & 2 & & & & 1 & & & 1 & 1 & & 4 & & 1 & 3 & & & & \\
\hline Lower ext. & 33 & 22 & 10 & & & 1 & & 1 & 1 & 3 & 1 & 4 & 2 & 7 & 1 & 3 & 4 & 2 & 2 & 1 & \\
\hline Eye & 67 & 30 & 26 & 1 & 2 & 1 & 1 & 1 & 2 & 6 & 5 & 8 & 4 & 11 & & 3 & 1 & 4 & 1 & 5 & 11 \\
\hline Mouth & 24 & 13 & 10 & & & & & 1 & & & 2 & 6 & 3 & 4 & & 2 & 1 & 2 & 1 & 1 & 1 \\
\hline Nose & 18 & 13 & 5 & & & & & & & 1 & 1 & 2 & 1 & 4 & & 2 & 6 & 1 & & & \\
\hline Female genital & 12 & & 12 & & & & 1 & & 1 & & 1 & & 1 & & & 7 & & 1 & & & \\
\hline Others & 7 & 6 & 1 & & & & & 2 & & & & 2 & & & & 1 & 2 & & & & \\
\hline Total & 206 & 112 & 81 & 3 & 2 & 3 & 4 & 8 & $4^{\prime}$ & 11 & 12 & 25 & 13 & 35 & 1 & 23 & 23 & 15 & 4 & 8 & 12 \\
\hline
\end{tabular}

Table I shows the incidence of malignant melanoma by site, sex and age collected from Japanese literature. There are five cases under nine years of age, three males and two females. Most of them seems to ralated with xeroderma pigmentosum though no detail description about this point could be found in any case.

TABLE II

Incidences of Malignant Melanoma by Sex

\begin{tabular}{|c|c|c|c|}
\hline Sex Authors & Dieterich & Macdonald & Yoshida \\
\hline $\begin{array}{l}\text { Male }(\%) \\
\text { Female }(\%)\end{array}$ & $\begin{array}{ll}74 & (55.7) \\
59 & (44.3)\end{array}$ & $\begin{array}{l}172 \\
177 \quad(59.3) \\
170.7)\end{array}$ & $\begin{array}{rr}112 & (58) \\
81 & (42)\end{array}$ \\
\hline
\end{tabular}

Table II is the comparison of the incidences of malignant malanoma by sex as reported by three authors, Dieterich (German, 1887), Macdonald (U.S.A., 1948) and the present author. There is no significant difference by sex in these reports.

The distribution of malignant melanomas by age groups is shown in Table III. There is no significant difference by sex. It occurs most frequently over forty, among males in 77.7 per cent of the cases and among females in 72.9 per cent. Similar data by four authors, Dieterich, Eiselt, 
TABLE III

Distribution of Malignant Melanomas by Age Groups

\begin{tabular}{|c|c|c|c|c|}
\hline \multirow{2}{*}{ Age } & \multicolumn{2}{|c|}{ Males } & \multicolumn{2}{|c|}{ Female } \\
\hline & Number & $\begin{array}{l}\text { Percentage of } \\
\text { distribution }\end{array}$ & Number & $\begin{array}{c}\text { Percentage of } \\
\text { distribution }\end{array}$ \\
\hline Under 9 & 3 & 2.7 & 2 & 2.5 \\
\hline $10-19$ & 3 & 2.7 & 4 & 4.9 \\
\hline $2 C-29$. & 8 & 7.1 & 4 & 4.9 \\
\hline $30-39$ & 11 & 9.8 & 12 & 14.8 \\
\hline $40-49$ & 25 & 22.3 & 13 & 16.1 \\
\hline $50-59$ & 35 & 31.3 & 23 & 28.4 \\
\hline $60-69$ & 23 & 20.5 & 15 & 18.5 \\
\hline 70 & 4 & 3.6 & 8 & 9.9 \\
\hline Total & 112 & 100.0 & 81 & 100.0 \\
\hline
\end{tabular}

TABLE IV

Distributions of Malignant Melanomas by Age Groups (\%)

\begin{tabular}{c|c|c|c|c|c}
\hline Age Authors & Dieterich & Eiselt & Macdonald & Yoshida & Authors Age \\
\cline { 1 - 3 } $11-10$ & 4.0 & & .9 & 2.6 & -9 \\
$21-30$ & 1.6 & 5.0 & 3.8 & 3.6 & $10-19$ \\
$31-40$ & 12.0 & 17.0 & 5.8 & 6.1 & $20-29$ \\
$41-50$ & 16.0 & 15.0 & 11.9 & 11.9 & $30-29$ \\
$51-60$ & 23.2 & 25.0 & 14.3 & 19.6 & $40-49$ \\
$61-70$ & 23.2 & 28.0 & 24.8 & 30.4 & $50-59$ \\
$70-$ & 18.4 & 10.0 & 20.4 & 19.6 & $60-69$ \\
& 1.6 & & 18.1 & 6.2 & $70-$
\end{tabular}

Macdonald and the present author, were compared with each other in Table IV. Excepting a fact that the percentage of the cases over seventy years of age reported by Macdonald is significantly higher, no significant difference by each author can be found. The remarkably higher value over seventy by Macdonald seems to be based on the fact that the people over seventy are more in the present U.S.A. than in the past Germany and Japan.

Table $\mathrm{V}$ gives the actual numbers and percentages of malignant melanoma in terms of organs primarily affected. It shows that there was a preponderance of involvement of the skin and eye as compared with other regions. Nagayo stated in his clinical statistic studies that skin cancers showed only 177. per cent of 20,782 cases of total cancer. Therefore it is considered that the skin is affected more frequently by 
TABLE V

Incidence of Malignant Melanoma in Terms of Organs Primarily Affected (collected from Japanese literature)

\begin{tabular}{|c|c|c|}
\hline Site & Male (\%) & Female $(\%)$ \\
\hline Skin & $50(44.6)$ & $27 \quad(33.3)$ \\
\hline Head and neck & $12(10.7)$ & $9(11.1)$ \\
\hline Upper extremity & $5 \quad(4.5)$ & $6 \quad(7.4)$ \\
\hline Trunk & $11 \quad(9.8)$ & $(2.4)$ \\
\hline Lower extremity & $22(19.6)$ & $10(12.4)$ \\
\hline Eye & $30 \quad(26.8)$ & $26 \quad(32.1)$ \\
\hline Mouth & $13(11.6)$ & $10(12.4)$ \\
\hline Nose & $13(11.6)$ & $5 \quad(6.2)$ \\
\hline Female genital & & $12(14.8)$ \\
\hline Others & $6 \quad(5.4)$ & $1 \quad(1.2)$ \\
\hline Total & $112(100.0)$ & $81(100.0)$ \\
\hline
\end{tabular}

TABLE VI

Incidences of Malignant Melanoma of the Skin by Site

\begin{tabular}{|c|c|c|c|c|c|}
\hline Site Authors & Dieterich & Luther & Macdonald & Sequeira & Yoshida \\
\hline Head and neck & $38(30.2)$ & & $65(26.5)$ & $2(4.1)$ & $21(26.9)$ \\
\hline Trunk & $40(31.7)$ & $198,(54.7)$ & $65(26.5)$ & $1(2.0)$ & $13(16.7)$ \\
\hline Upper ext. & $13(10.3)$ & $48(13.3)$ & $41(16.7)$ & $4(8.2)$ & 11 (14.1.) \\
\hline L.ower ext. & $35(27.3)$ & $116(32.0)$ & $74(30.3)$ & $42(85.7)$ & $33(42.3)$ \\
\hline
\end{tabular}

malignant melanoma than by other cancer.

Table VI presents the incidences of malignant melanoma of the skin by site reported by five authors, Dicterich, Luther, Macdonald, Seuqeira and the present author. Sequeira made a study of the natives of East and Central Africa and the present author collected Japanese cases including a few from other yellow races. The other authors showed the data from the white races including a few cases of negroes (three cases in Macdonald's). Lower extremities especially soles have been admitted as the most faboritest location of malignant melanoma. As Table VI reveals, lower extremities are most frequently affected among African ngroes in 85.7 per cent and next often among the Japanese, a yellow race, in 42.3 per cent. Among the white races, on the other hand, the affection of these parts have relatively lower value, 22.8-32.0 per cent. There are differences between three races in the conditions of usual life, e.g. walking with bare feet in the black races. And it cannot be denied that 
the influence by the trauma, which seems to occur in different degrees, plays one role in the above-mentioned data. However, if the trauma is the only causative factor in the preponderance of involvement of the lower extremity in malignant melanomas of the skin, a similar fact should be found in the skin carcinoma. As a matter of fact, Tsutusui (Japan, 1910) found only 4.3 per cent of 70 cases of skin carcinoma to occur primarily in either upper or lower extremities. From this, the trauma seems not to be the only and chief cause of the above-mentioned fact. The author thinks it more reasonable to consider this fact as follows: It has been admitted that malignant melanoma are not commonly found in the darker races. (But Sequeira described that it occurs more frequently in the natives of East and Central Africa than in the white races.) It occurs more rarely also in the Japanese than in the white races. In other words, the white races whose skin is scarcely pigmented are more frequently affected by malignant melanoma than the darker races do whose skin is ordinarily deeply pigmented except soles and a few other regions. From this, it can be inferred that malignant melanoma occurs more frequently in the regions which are ordinarily not deeply pigmented and so it occurs relatively equally in all regions of the skin of the white races and very frequently in the soles of the darker races. Thus the author advocates as follows: (1) when the pigmentation occurs in the regions which are not commonly pigmented, it is easy to take malignant cource, (2) pigmented nevus in similar regions has malignant potentiality. The high incidence of melanotic tumors in old gray horses especially in the hoofs or in white cattle is favourable to this advocation.

TABLE VII

Precursor Lesions

\begin{tabular}{l|c|c}
\hline & Number of cases & $\%$ \\
\hline $\begin{array}{l}\text { Naevus pigmentosus } \\
\text { (containing-lentigo) }\end{array}$ & 45 & 57.7 \\
$\begin{array}{l}\text { Other lesions } \\
\text { no I.esions and not } \\
\text { stated }\end{array}$ & 13 & 16.7 \\
\hline Total & 20 & 25.6 \\
\hline 78 & 100.0
\end{tabular}

Table VII shows precursor lesions of 77 malignant melanomas originated in the skin. In 57.7 per cent of the cases there was a history of previously existing nevus pigmentosus or lentigo and in 16.7 per cent a history was obtained of other skin lesions, e.g. clavus, wart, scar or ulcer. In 25.6 per cent of the cases there was no history of previously 
existing lesions or no statement of this point. Dieterich observed a history of nevus pigmentosus or wart in 37, or 25.5 per cent, of 145 cases of malignant melanoma and Luther admitted pre-existent nevus as a precursor lesion in 32 per cent of 471 cases. Driver and Macvicar ${ }^{111}$ observed a history of a previously existing pigmented lesion in 48 , or 80 per cent, of their 60 cases of Americans containing two negroes. Sequeira, on the other hand, described as follows: "There is no evidence of naevus pigmentosus. In a few instances crab yows was and antecedent, but whether it is causal is not clear." These results, however, are very different depending upon their methods of examination. Therefore, it seems difficult to come to a definite conclusion on the differences between these races.

A history of previous trauma was described in 31 , or 39.7 per cent, of 78 malignant melanomas originated in the skin, e.g. medical treatment as excision, incision, electric or medical cauterization and physical irritation as rubbing or scratching. In 47 cases, there was no similar history or no statement of this point. Luther observed a history of trauma only in 32, or 6.9 per cent, of 471 cases, but Driver and Macvicar admitted similar fact in 35 , or 58.3 per cent, of 60 cases. However, it must be forgotten that continous irritations may be taken as playing a role unconsciously. The author described above that malignant melanoma occurs more frequently in the regions which are ordinarily not deeply pigmented. But the soles are affected more frequently than the palms (esp. in the black races) though both regions are equally nonpigmented. This can be explained by the fact that the soles receive usualy a continuous irritations especially in the black races. Pack gave a serious consideration only to chronic irritation. The trauma especially continuous irritation seems to take a role, though not single but not chief, in the development of malignant melanoma.

Metastasis was evidenced in 52, or 66.7 per cent, of 78 malignant melanomas originated in the skin. In 19.2 per cent of the cases there was no metastasis and in 14.1 per cent no statement of this point. Macdonald described that among males, 63.9 per cent of the total, not only of the skin, had metastasis and among females, 54.8 per cent had metastasis. Sequeira, on the other hand, described that metastases occur in African negroes but they are far rarer than in Europeans. However, different authors used different examinations and so it seems to be unreasonable to conclude from only this point that this disease is "locally malignant (Sequeira)" in the darker races.

The death of the patient was reported in 24 cases, or 30.8 per cent, of 78 malignant melanomas originated in the skin, and only 3 cases were reported as cured. In 51 cases, there was no statement of this point. Since the methods of observation of the different authors of the prognosis 
are very different from each other, it seems to be impossible to comparethese data with one another. However, it is supposed that the last group contains not a fey cases which must be transferred to the first group. Therefore, it is advocated that malignant melanoma in the Japanese as. a yellow race connot be considered to be "locally malignant."

\section{Summary and Conclusion}

A statistical study on 206 cases of malignant melanoma collected from Japanese literaure from 1890 to 1949 was made as compared with those in the white or black races.

1. Malignant melanomas are more rarely found in the Japanesethan in the white races and the ratio of this disease to total cancer in Japan is lower than that in Connecticut (U.S.A.).

2. The incidence of malignant melanoma by sex shows no significant difference in both the yellow and white races. The distribution of this disease by age groups presents no significant difference in two sexes and the highest percentage over forty years of age in both the yellow and white races.

3. The incidences of malignant melanoma of the skin by site in the white, yellow and black races were compared with each other. Lower extremities especially the soles which are ordinarily nonpigmented are most frequently affected among African negroes and next often among the Japanese, yellow race. Among the white races, however, the affection of these parts have relatively lower percentage. It is admitted, on the other hand, that the white races whose skin is scarcely pigmented are more frequently affected by malignant melanoma than the darker races do whose skin is ordinarily deeply pigmented except soles and a few otherregions. These facts cannot be expalined only by the influence of thetrauma, which seems to occur in different degrees in these races. The author advocate as follows: (1) when the pigmentation occurs in the regions which are not commonly pigmented, it is easy to take malignant cource, (2) pigmented nevus in similar regions has malignant potentiality.

4. The problems of precursor lesions, history of previous trauma, metastasis and prognosis were studied statistically. Since the results arevery different depending upon the methods of examination, it is difficult to come to a definite conclusion showing the differences between the races. However, it is supposed that malignant melanoma in the Japanese cannot be considered to be "locally malignant."

\section{References}

1) Itô and Yoshida, Tohoku J. Exp. Med. 1952, 55, Suppl., 60.

2) Dieterich, Arch. f. klin. Chir., 1887, 35, 289. 
3) Sequeira and Vint, Brit. J. Dermat. and Syph., 1934, 46, 361.

4) Pack et al., Calfornia Med., 1947, 66, 283.

5) Macdonald, in the Biology of Melanomas, New York 1948, 71.

6) Kawanishi, Nihon-Geka-Gakkaishi (Jap. J. Chir.), 1928, $29,503$.

7) Miyata, Jitchi-Ika-Rinsho (Jap.), 1935, 12, 1069.

8) Amano, Taikyu-Ishi (Jap.), 1941, 3, 41.

9) Fujita, Rinsho-Geka (Jap.), 1948, 3, 480.

10) Nagayo, Gan (Cancer), 1933, Suppl. 1.

11) Driver and Macvicar, J.A.M.A., 1943, 121, 413. 